\title{
Nutrientes foliares de espécies arbóreas de três estádios sucessionais de floresta ombrófila densa no sul do Brasil
}

\author{
Maria Regina Torres Boeger ${ }^{1,3}$, Celina Wisniewski² e Carlos Bruno Reissmann ${ }^{2}$
}

Recebido em 17/08/2002. Aceito em 17/08/2004

\begin{abstract}
RESUMO - (Nutrientes foliares de espécies arbóreas de três estádios sucessionais de floresta ombrófila densa no sul do Brasil). As concentrações de macro e micronutrientes foliares de espécies arbóreas foram avaliadas em três estádios sucessionais (inicial, intermediário e avançado) de uma floresta ombrófila densa das terras baixas, no litoral do Estado do Paraná, crescendo sobre solo arenoso e oligotrófico. Dentre as espécies arbóreas mais importantes de cada estádio sucessional (quatro iniciais; oito intermediárias; 11 avançadas), coletou-se folhas maduras de cinco diferentes indivíduos de cada estádio sucessional para a análise química dos seguintes elementos: $\mathrm{N}$, $\mathrm{P}, \mathrm{K}, \mathrm{Ca}$, $\mathrm{Mg}, \mathrm{C}, \mathrm{Zn}, \mathrm{Fe}, \mathrm{Cu}$ e Mn. As espécies do estádio inicial possuem as menores concentrações médias foliares de N, P, K, Zn, Fe e a maior concentração de $\mathrm{Mg}$ e estas concentrações são estatisticamente diferentes ( $p<0,05)$, quando comparadas com os valores médios dos demais estádios. Nos estádios intermediário e avançado, as concentrações médias de N, Ca e Mg, assim como os micronutrientes estão dentro dos valores esperados para florestas tropicais. As concentrações médias de K, nos estádios inicial e intermediário, e as concentrações médias de $\mathrm{P}$, em todos os estádios, encontram-se abaixo dos valores reportados para as florestas tropicais. A relação C/N é alta (>25:1), apesar da tendência de diminuir à medida que avança a sucessão. O aumento da concentração da maioria dos nutrientes foliares analisados ao longo do gradiente sucessional está associado, possivelmente, com o incremento do acúmulo da serapilheira sobre o solo, o que proporciona ciclagem de nutrientes mais intensa e maiores concentrações de nutrientes no solo.
\end{abstract}

Palavras-chave: concentração de nutrientes foliares, sucessão, Mata Atlântica, floresta ombrófila densa

ABSTRACT —(Leaf nutrient content of tree species from three successional stages of tropical rain forest in south Brazil). We investigated the leaf nutrient content of trees species from three distinct successional stages (early, intermediate, late) of a lowland rain forest located near the coast of Paraná State, Brazil. This forest grows on sandy soil with low nutrient content. We collected mature leaves from five different individuals of each sucessional stages of the most important tree species of each successional stage (four of the early; eight of the intermediate and 11 of the late stages) for chemical analysis of following elements: $\mathrm{N}, \mathrm{P}, \mathrm{K}, \mathrm{Ca}, \mathrm{Mg}, \mathrm{C}, \mathrm{Zn}, \mathrm{Fe}, \mathrm{Cu}$ e $\mathrm{Mn}$. The species from early sucessional stage have lower contents of $\mathrm{N}, \mathrm{P}, \mathrm{K}, \mathrm{Zn}, \mathrm{Fe}$, and higher contents of $\mathrm{Mg}$. These concentrations are statistically different $(\mathrm{p}<0,05)$ when compared to mean values of the other stages. For the intermediate and late successional stages, the average nutrient concentrations of $\mathrm{N}, \mathrm{Ca}, \mathrm{Mg}$ and micronutrients are within the range of values expected for tropical forests. Foliar $\mathrm{K}$ concentration, from early and intermediate successional stages, and foliar $\mathrm{P}$ concentration, for all successional stages, are below the reported range of values for tropical forests. The $\mathrm{C} / \mathrm{N}$ ratio is high $(>25: 1)$, despite of the tendency to decrease as succession advances. The increment of concentration of the most studied foliar nutrients along the successional gradient is probably related to the accumulation of litter above the soil that provides a more adequate environment for efficient nutrient cycling and higher nutrient concentration in the soil.

Key words: leaf nutrient content, succession, atlantic forest, tropical rain forest

\section{Introdução}

O estado nutricional das plantas tem sido objeto de estudo por várias décadas, principalmente de plantas de interesse econômico (Malavolta 1980). Mais recentemente, ecólogos têm investigado as concentrações nutricionais das plantas de diferentes formações florestais e a ciclagem de nutrientes dentro destes ecossistemas (Golley et al. 1978; Chapin III 1980; Haag
1985; Cunha et al. 1993; Magalhães \& Blum 1999; Muoghalu 2003; Niinemets \& Kull 2003). A baixa disponibilidade de alguns nutrientes, como $\mathrm{Ne}$, assim como as adaptações das plantas a estes baixos níveis têm recebido especial atenção, principalmente nos trópicos (Chapin III 1980; Jordan 1985; Medina et al. 1990; Drechsel \& Zech 1991; Bergmann et al. 1994; Turner et al. 1995; Kapelle \& Leal 1996; Aerts \& Chapin III 2000).

\footnotetext{
${ }^{1}$ Universidade Federal do Paraná, Departamento de Botânica, Setor de Ciências Biológicas, C. Postal 19031, CEP 81531-990, Curitiba, PR, Brasil

2 Universidade Federal do Paraná, Departamento de Solos, Setor de Ciências Agrárias, CEP 81531-990, Curitiba, PR, Brasil (cewisni@agrarias.ufpr.br; reissmann@ufpr.br)

3 Autor para correspondência: rboeger@ufpr.br
} 
A análise de nutrientes foliares tem se mostrado bom indicador do estresse nutricional de várias espécies, especialmente por comparação de plantas com pouco e ótimo suprimento de nutrientes (Malavolta 1980). A concentração de nutrientes foliares varia de acordo com a sazonalidade, idade da folha (Sobrado \& Medina 1980; Marin \& Medina 1981), luz disponível (Drechsel \& Zech 1991), lixiviação (Waring \& Schlesinger 1985; Marschner 1986) e o tipo de solo florestal (Vitousek \& Stanford 1986; Thompson et al. 1992). Em alguns ecossistemas florestais, as folhas jovens tendem a ter maiores concentrações de N, P e K. À medida que as folhas envelhecem, ocorre diminuição destes nutrientes, enquanto as concentrações de $\mathrm{Ca}, \mathrm{Mg}$ e Fe aumentam, em função dos processos de translocação dos nutrientes e do acúmulo dos produtos fotossintéticos na folha (Binkley 1986; Marin \& Medina 1981). Considerando-se a fertilidade do solo, solos arenosos (espodossolos) possuem vegetação com baixa concentração de N e P nas folhas e concentrações intermediárias de cátions, enquanto latossolos possuem vegetação com maiores concentrações de N, mas com baixas concentrações de K (Vitousek \& Stanford 1986; Thompson et al. 1992).

Para as florestas tropicais, são poucos os estudos que investigam a concentração de nutrientes foliares. Vitousek \& Sanford (1986), Drechsel \& Zech (1991) e Noij et al. (1993) apresentaram as concentrações médias dos principais nutrientes foliares em florestas tropicais de diferentes localidades e discutiram a variação destas concentrações de acordo com o tipo de solo. Porém, deve-se considerar que as formações florestais tropicais são bastante heterogêneas, apresentando grande diversidade de espécies com diferentes formas de vida e ciclos vitais, ocorrendo sobre grande variedade de solos e climas, em diferentes condições de estresse hídrico. Como resultado, as concentrações de nutrientes associadas com as deficiências diferem caso a caso e as concentrações ótimas ainda não foram claramente definidas para as plantas destes sistemas (Drechsel \& Zech 1991).

Os estudos de nutrientes de espécies nativas das florestas brasileiras concentram-se na Floresta Amazônica (Klinge et al. 1983; Klinge 1985; Thompson et al. 1992; Magalhães \& Blum 1999; Neves et al. 1999; Johnson et al. 2001; Parolin et al. 2002), Floresta Atlântica (Golley et al. 1978; Moraes \& Domingos 1997; Moraes et al. 1999) e Floresta com Araucária (Reissmann et al. 1983; Britez et al. 1992). Mais atenção tem-se dado aos estudos de ciclagem de nutrientes, enfocando a produção e decomposição da serapilheira em diversas formações florestais brasileiras (Meguro et al. 1979; Meguro \& Delitti 1985; Domingos et al. 1997; Mello \& Porto 1997; Moraes et al. 1999; Villela \& Proctor 1999; Martins \& Rodrigues 1999).

Os solos tropicais, principalmente os arenosos que ocorrem nas planícies litorâneas brasileiras, são conhecidos por sua baixa fertilidade, devido à alta lixiviação e intemperismo aos quais são impostos (Vitousek \& Sanford 1986; Whitmore 1998). Segundo Chapin III (1980), os solos inférteis como os arenosos são dominados por espécies de crescimento lento, devido à sua baixa capacidade de fotossíntese e absorção de nutrientes. O requerimento anual de nutrientes destas espécies é baixo porque a produção de tecidos é lenta e a taxa da perda de nutrientes, através da lixiviação e senescência das folhas, é baixa. Por outro lado, essas plantas maximizam a aquisição de nutrientes através da manutenção de uma grande biomassa radicular, normalmente associada às micorrizas e uma lenta reposição de raízes (Aerts \& Chapin III 2000).

As estratégias acima citadas também foram identificadas em espécies pioneiras de florestas secundárias tropicais mexicanas de solos inférteis, abandonados após o cultivo (Gómez-Pompa \& Vásquez-Yanes 1974). A competição por nutrientes é um dos fatores decisivos no processo sucessional nestes ambientes (Rode 1995) e a sucessão resulta de um gradiente temporal das disponibilidades relativas dos recursos limitantes de luz e nutrientes no solo (Tilman 1985; Guariguata \& Ostertag 2001). As espécies pioneiras geralmente necessitam restaurar a fonte de nutrientes. Estas espécies devem possuir requerimentos nutricionais muitos baixos e usar sistemas muito eficientes para absorver e utilizar os nutrientes que se encontram em pequena quantidade no solo. As espécies secundárias podem reciclar nutrientes em maior quantidade do que as espécies primárias e algumas plantas podem restaurar o $\mathrm{P}$ e o $\mathrm{K}$ nas camadas mais superficiais do solo. Isto explicaria porque algumas espécies podem se estabelecer em solos inférteis (Kellman 1969).

Os estudos sobre florestas tropicais secundárias que se desenvolvem após o abandono de áreas utilizadas para a agricultura são recentes, uma vez que o processo de desflorestamento intensificou-se no século XX (Guariguata \& Ostertag 2001). Os processos sucessionais que ocorrem nas florestas secundárias são especialmente importantes para o entendimento das mudanças que ocorrem tanto na estrutura da vegetação, 
quanto nos processos de bioacumulação, produtividades primária e secundária, além da ciclagem de nutrientes (Rode 1993; Chandrashekara \& Ramakrishnan 1994). Nas áreas tropicais úmidas a sucessão é mais pronunciada, ocorrendo num tempo mais curto do que nas áreas temperadas. Apesar disto, são poucos os estudos sobre os processos sucessionais, nos trópicos (Gómez-Pompa \& Vázques-Yanes 1974; Kappelle et al. 1995; Herrera \& Finegan 1997; Guariguata \& Ostertag 2001; Chinea 2002; Muoghalu 2003). Para as florestas tropicais brasileiras, os estudos sobre sucessão são relacionados com a distribuição de espécies (Uhl et al. 1981) regeneração natural (Salimon \& Negrelle 2001); assimilação de nutrientes em florestas oligotróficas (Uhl \& Jordan 1984; Reich et al. 1995; Zangaro et al. 2003) e produção de serapilheira (Domingos et al. 1997; Boeger et al. 2000).

Este estudo é parte de um projeto desenvolvido no litoral paranaense, cujo objetivo foi avaliar as modificações ocorridas na comunidade vegetal e no solo, em três estádios sucessionais distintos de Floresta Ombrófila Densa das Terras Baixas. Para tanto, foram efetuados os seguintes estudos em cada estágio sucessional: composição florística e estrutura fitossociológica do estrato arbóreo; caracterização morfológica, física e química do perfil do solo; características químicas e granulométricas das camadas superficiais do horizonte A do solo, produção de serapilheira e deposição de nutrientes; taxa de decomposição e liberação de nutrientes da serapilheira; caracterização morfológica e química e estimativa da espessura e quantidade acumulada dos horizontes orgânicos do solo (Celina Wisniewski, dados não publicados).

Este trabalho teve como objetivos determinar as concentrações médias dos macro e micronutrientes foliares das espécies arbóreas ocorrentes em cada estádio sucessional; comparar os valores médios das concentrações de nutrientes entre os estádios sucessionais e relacionar as diferenças das concentrações de nutrientes encontradas entre os estádios com as condições de fertilidade do solo, representado pela produção da serapilheira e pela composição química dos horizontes orgânicos do solo. Adicionalmente, os dados obtidos foram comparados com os de outras formações florestais tropicais.

\section{Material e métodos}

Esse estudo foi realizado no Parque Estadual do Palmito $\left(25^{\circ} 35^{\prime} \mathrm{S}\right.$; $48^{\circ} 32^{\prime} \mathrm{O}$ Gr.), de propriedade da empresa BANESTADO S.A. Reflorestadora, localizada no Município de Paranaguá, PR, com 1.780ha. Esta região é climaticamente caracterizada como Af: tropical, superúmido, sem estação seca e isenta de geadas, de acordo com a classificação de Köeppen. A temperatura média anual é de $21,9^{\circ} \mathrm{C}$, sendo que a temperatura média do mês mais quente é de $25^{\circ} \mathrm{C}$ e a do mês mais frio é de $18^{\circ} \mathrm{C}$ (Maack 1981; Britez et al. 1997). A precipitação média anual é de $1.959 \mathrm{~mm}$, sendo janeiro e fevereiro os meses mais chuvosos. Há distribuição uniforme das chuvas ao longo do ano. A média anual da umidade relativa do ar é em torno de $85 \%$ (Maack 1981; IAPAR 1994). A vegetação do Parque é classificada como Floresta Ombrófila Densa das Terras Baixas estando dentro do domínio da Mata Atlântica. Esta formação caracteriza-se por ser pouco exuberante, com árvores de porte médio ( 5 a $20 \mathrm{~m}$ alt.), repetindo quase sempre o mesmo padrão florístico e estrutural por toda a sua extensão (Veloso et al. 1991). Atualmente, o Parque encontra-se coberto com vegetação em diferentes fases sucessionais, após o abandono das culturas ali praticadas no passado.

Em estudos anteriores nesse Parque, foram escolhidas três diferentes áreas cujas idades, após o abandono do cultivo de mandioca, são de 17, 30 e 55 anos (ano base 2000, que corresponde ao ano inicial do estudo), respectivamente. Em cada área foi demarcada uma parcela de $200 \mathrm{~m}^{2}$, no interior da mata, de forma aleatória, onde foram realizados levantamentos florístico e fitossociológico do estrato arbóreo (Silvia Ziller, dados não publicados), além do estudo de produção e decomposição da serapilheira e caracterização do solo (Celina Wisniewski, dados não publicados).

Para as três áreas, o solo é arenoso, classificado como espodossolo não hidromórfico, álico, A moderado, textura arenosa, relevo plano (EMBRAPA 1984). Entretanto, existem diferenças na espessura e profundidade dos horizontes, assim como no grau de consistência do horizonte espódico entre as três áreas. No estádio inicial, o horizonte A tem uma espessura média de $30 \mathrm{~cm}$ e é distrófico, enquanto que nos estádios intermediário e avançado a espessura é em torno de $25 \mathrm{~cm}$ e álico. O horizonte espódico (Bh) variou de 60 a $110 \mathrm{~cm}$ no estádio inicial e intermediário e no estádio avançado de 20 a $55 \mathrm{~cm}$. Em todos os estádios, o horizonte espódico é distrófico. Porém, apenas no estádio inicial, o grau de consistência não é uniforme. A espessura média total dos horizontes orgânicos no estádio inicial é de $1,61 \mathrm{~cm}$, no estádio intermediário de $5,15 \mathrm{~cm}$ e no estádio avançado de $5,02 \mathrm{~cm}$, e a produção 
anual de serapilheira apresentou diferenças, principalmente entre o estádio inicial $\left(4,7\right.$ ton $\left.\cdot \mathrm{ha}^{-1}\right)$ e os demais estádios $\left(7,8\right.$ ton.ha $\left.\mathrm{h}^{-1}\right)$. Entretanto, as características químicas e granulométricas do solo mineral, ao longo do processo sucessional, apresentaram apenas pequenas modificações como o $\mathrm{pH}$, que diminuiu, e o aumento do teor de $\mathrm{Al}$, à medida que avançou a sucessão (Celina Wisniewski, dados não publicados).

Os estádios sucessionais também apresentaram diferenças quanto à estrutura e fitodiversidade do componente arbóreo. No estádio sucessional inicial, 15 espécies arbóreas foram identificadas, com $4 \mathrm{~m}$ alt., em média, formando apenas um estrato. No estádio intermediário, 23 espécies arbóreas foram registradas, com cerca de $12 \mathrm{~m}$ alt., com dois estratos definidos. No estádio avançado, 50 espécies arbóreas foram identificadas, cujo estrato superior atingiu $14 \mathrm{~m}$ alt. Com base no levantamento florístico e fitossociológico, algumas espécies foram selecionadas em cada parcela, cujos critérios foram o número mínimo de indivíduos $(\mathrm{n}=5)$ por espécie na parcela e o maior índice de Valor de Importância da espécie em cada estádio. Assim, devido à diferença na fitodiversidade de cada estádio e dos critérios previamente citados, o número de espécies selecionadas para o estudo variou entre os estádios sucessionais. As espécies selecionadas nos diferentes estádios sucessionais foram: estádio sucessional inicial (17 anos); Ilex theezans Mart. ex Reissek (Aquifoliaceae), Psidium cattleyanum Sabine (Myrtaceae), Ocotea pulchella Mart. (Lauraceae) e Ternstroemia brasiliensis Camb. (Theaceae); estádio sucessional intermediário (30 anos), Ilex theezans Mart. ex Reissek (Aquifoliaceae), Ternstroemia brasiliensis Camb. (Theaceae), Rapanea venosa (DC) Mez. (Myrsinaceae), Gomidesia fenzliana Berg. (Myrtaceae), Clusia criuva (Sald.) Engl. (Clusiaceae), Ocotea pulchella Mart. (Lauraceae), Psidium cattleyanum Sabine (Myrtaceae) e Callophyllum brasiliensis Camb. (Clusiaceae); estádio sucessional avançado (55 anos), Tapirira guianensis Aubl. (Anacardiaceae), Ocotea aciphylla (Ness) Mez. (Lauraceae), Ocotea pulchella Mart. (Lauraceae), Callophyllum brasiliensis Camb. (Clusiaceae), Pouteria beaurepairei (Glaz \& Raunk) Bachni (Sapotaceae), Myrcia racemosa (Berg.) Kiaerzk (Myrtaceae), Ternstroemia brasiliensis Camb. (Theaceae), Pera glabrata (Schott.) Baill (Euphorbiaceae), Ilex theezans Mart. ex Reissek (Aquifoliaceae), Amaioua guianensis Aubl. (Rubiaceae) e Gomidesia fenzliana Berg.
(Myrtaceae). Algumas espécies ocorreram em mais de um estádio, a saber: Ilex theezans (estádios inicial, intermediário e avançado), Psidium cattleyanum (estádios inicial e intermediário), Ocotea pulchella (estádios inicial, intermediário e avançado); Ternstroemia brasiliensis (estádios inicial, intermediário e avançado); Callophyllum brasiliensis (estádios intermediário e avançado) e Gomidesia fenzliana (estádios intermediário e avançado).

Para cada espécie estudada, em cada estádio sucessional, foram coletadas folhas de sol, totalmente expandidas e maduras, sem marcas aparentes de predação ou parasitismo, voltadas para a face norte. Trinta folhas localizadas a partir do quarto nó, a partir do ápice foram coletadas para cada um dos cinco indivíduos diferentes, por espécie, por estádio sucessional, para análise das concentrações de nutrientes. As folhas foram secas a $60^{\circ} \mathrm{C}$, até peso constante, moídas em moinho elétrico da marca Wiley, homogeneizadas e submetidas à análise química para a determinação das concentrações de macronutrientes: Nitrogênio $(\mathrm{N})$, Fósforo (P), Potássio (K), Cálcio $(\mathrm{Ca})$, Magnésio $(\mathrm{Mg})$ e Carbono $(\mathrm{C})\}$ e de micronutrientes \{Ferro (Fe), Manganês (Mn), Cobre (Cu) e Zinco ( $\mathrm{Zn})\}$, utilizandose a metodologia descrita por Tedesco et al. (1995). O $\mathrm{N}$ foi determinado pelo processo macro Kjeldahl, conforme descrito em Hildebrand et al. (1977). O preparo e a digestão das amostras para o referido elemento foi a úmida com $\mathrm{H}_{2} \mathrm{SO}_{4}$ concentrado, com posterior destilação com $\mathrm{NaOH}$ a $32 \%$, e titulação ácida do $\mathrm{NH}_{4}$ (Jones \& Case 1990). A digestão dos outros elementos foi feita através da queima do material moído em mufla à $500^{\circ} \mathrm{C}$, em duas etapas de 3 horas e solubilização das cinzas em $\mathrm{HCl} 10 \%$, conforme descrito em Hildebrand et al. (1977) e Reissmann et al. (1994). No extrato, foram determinado $\mathrm{Ca}, \mathrm{Mg}, \mathrm{Fe}$, $\mathrm{Mn}, \mathrm{Cu}, \mathrm{Zn}$, por absorção atômica e $\mathrm{K}$ por emissão em espectrofotômetro de absorção atômica Perkin-Elmer 2380 (Jones \& Case 1990). O P foi determinado no mesmo estrato pelo método colorimétrico vanadatomolibdato de amônio (cor amarela), sendo as leituras feitas em espectrofotômetro UV/VIS Perkin-Elmer 554 (Malavolta et al. 1989). O C total foi determinado pelo método de Walkley e Black, via úmida (EMBRAPA 1979). As amostras foram analisadas no Laboratório de Nutrição de Plantas do Departamento de Solos, UFPR, com exceção do C, que foi dosado no Laboratório de Solos e Tecnologia Vegetal do Instituto Agronômico do Paraná, Londrina, PR.

Para a análise estatística dos três estádios sucessionais, foi utilizada Análise de Variância 
Multivariada (MANOVA), com o programa STATISTICA 6.0 (Statsoft, Tulsa, OK, USA). Para a comparação das espécies arbóreas entre os três estádios sucessionais, assumiu-se que os grupos possuem a mesma matriz de covariância. Assim, a hipótese que se desejou testar é de que não há efeito significativo da idade dos estádios (E) para as concentrações de nutrientes, ou seja: $\mathrm{H}_{0}: \mathrm{E}_{1}=\mathrm{E}_{2}=\mathrm{E}_{3}$. Para testar esta hipótese, foi utilizada a estatística lambda de Wilks que tem distribuição de probabilidade aproximada F de Snedecor com graus de liberdade $2 p$ e 2(n-p-2), onde p é o número de variáveis envolvidas e n é o número de espécies dos três estádios (23). Para verificação das diferenças significativas de forma pareada entre as áreas foi utilizado o teste de comparação múltipla LSD (menor diferença significativa). Para as espécies que ocorrem em mais de um estádio sucessional, foi utilizada a análise de variância (oneway ANOVA) para verificar as diferenças significativas entre as áreas, por espécie e por nutriente.

\section{Resultados e discussão}

Entre os macronutrientes, os valores médios de concentração de Ca, nos estádio intermediário $(56,3 \%)$ e avançado (57,3\%), foram os que apresentaram maior coeficiente de variação. $O$ valor médio de concentração de $\mathrm{N}$ foi o que apresentou maior coeficiente de variação (38,9\%), no estádio inicial. O macronutriente com menor coeficiente de variação foi o $\mathrm{C}$ (inicial $=4,7 \%$; intermediário $=4,1 \%$ e avançado $=3,9 \%$ ), em todos os estádios. A análise estatística (MANOVA) mostrou que algumas das concentrações médias dos macronutrientes $(\mathrm{N}, \mathrm{P}, \mathrm{Mg}$ e $\mathrm{K})$ diferem estatisticamente $(p<0,05)$ entre os três estádios sucessionais. Entretanto, estes nutrientes apresentaram comportamentos distintos entre si. O único elemento que apresenta as concentrações médias significantemente diferentes $(\mathrm{p}<0,05)$ entre os três estádios é o $\mathrm{Mg}$, diminuindo à medida que avança a sucessão. Ao contrário, as concentrações médias de $\mathrm{N}$ e $\mathrm{K}$ tendem a ser maiores quanto mais antigo foi o estádio. Entretanto, as concentrações médias de $\mathrm{N}$ e K diferem estatisticamente $(\mathrm{p}<0,05)$ apenas entre o estádio avançado e os demais estádios. O P, apesar de também mostrar tendência de aumento das concentrações médias ao longo da sucessão, só difere estatisticamente $(\mathrm{p}<0,05)$ entre os estádios inicial e avançado. Os valores médios das concentrações de $\mathrm{Ca}$ e $\mathrm{C}$ não diferem significantemente $(p>0,05)$ entre os três estádios sucessionais (Tab. 1).
As concentrações médias do $\mathrm{N}$ foliar nos dois primeiros estádios (Tab. 2) estão dentro dos valores reportados para as florestas tropicais maduras sobre espodossolos (Vitousek \& Sanford 1986; Noij 1993). No estádio avançado, a concentração média deste nutriente ultrapassa os limites superiores reportados por estes autores, sendo semelhante aos valores verificados para restinga paludosa e para florestas ombrófilas densas de terras baixas (Tab. 2; Grubb 1977; Thompson et al. 1992). No estádio inicial, a concentração média de $\mathrm{N}$ está próxima daquelas reportados para restinga seca (Britez et al. 1997; Moraes \& Domingos 1997), floresta esclerófila seca (Marin \& Medina 1981) e para florestas tropicais sobre espodossolos (Vitousek \& Sanford 1986). A concentração média de $\mathrm{N}$ foliar é maior no estádio avançado e estatisticamente diferente dos demais estádios $(\mathrm{p}<0,05)$. Isto é conseqüência, provavelmente, do incremento de matéria orgânica no solo, que pode ser observado pela diferença de espessura dos horizontes orgânicos, ao longo do gradiente sucessional, (espessura total dos horizontes orgânicos no estádio inicial: $1,61 \mathrm{~cm}$; no estágio intermediário: $5,15 \mathrm{~cm}$ e no estádio avançado: $5,02 \mathrm{~cm}$ ), assim como as respectivas concentrações de $\mathrm{N}$ nos horizontes orgânicos (estádio inicial: $8,5 \mathrm{~g} \cdot \mathrm{kg}^{-1}$, estádio intermediário: $12,5 \mathrm{~g} \cdot \mathrm{kg}^{-1} \mathrm{e}$ estádio avançado: $13,7 \mathrm{~g} \cdot \mathrm{kg}^{-}$ 1, Celina Wisnieski, dados não publicados).

As concentrações médias de $\mathrm{P}$ foliar de todos os estádios sucessionais estão abaixo da média reportada para outras florestas tropicais (Vitousek \& Stanford 1986, Tab. 2). Os dados obtidos corroboram com os resultados de vários autores que concluíram que o $\mathrm{P}$ está quase sempre em baixo suprimento nas florestas tropicais (Medina et al. 1990; Thompson et al. 1992; Turner et al. 1995), devido ao alto intemperismo dos solos e aos processos de imobilização deste nutriente no solo (Waring \& Schlisinger 1985).

Estudos sobre concentrações de $\mathrm{N}$ e $\mathrm{P}$ foliares de espécies arbóreas em gradientes sucessionais em solos inférteis na Amazônia apresentaram resultados diferentes dos encontrados neste estudo (Reich et al. 1995). Nestas espécies amazônicas, as concentrações de $\mathrm{N}$ e $\mathrm{P}$ não diferiram significantemente entre as espécies dos estádios inicial, intermediário e avançado (Tab. 2). Segundo os autores, isto ocorre em função da maior plasticidade fenotípica das espécies do estádio inicial no incremento da capacidade fotossintética por aumento da concentração de $\mathrm{N}$ foliar. Porém, é importante ressaltar que os estádios sucessionais estudados por Reich et al. (1995) possuem idades diferentes dos estádios investigados no estudo aqui 


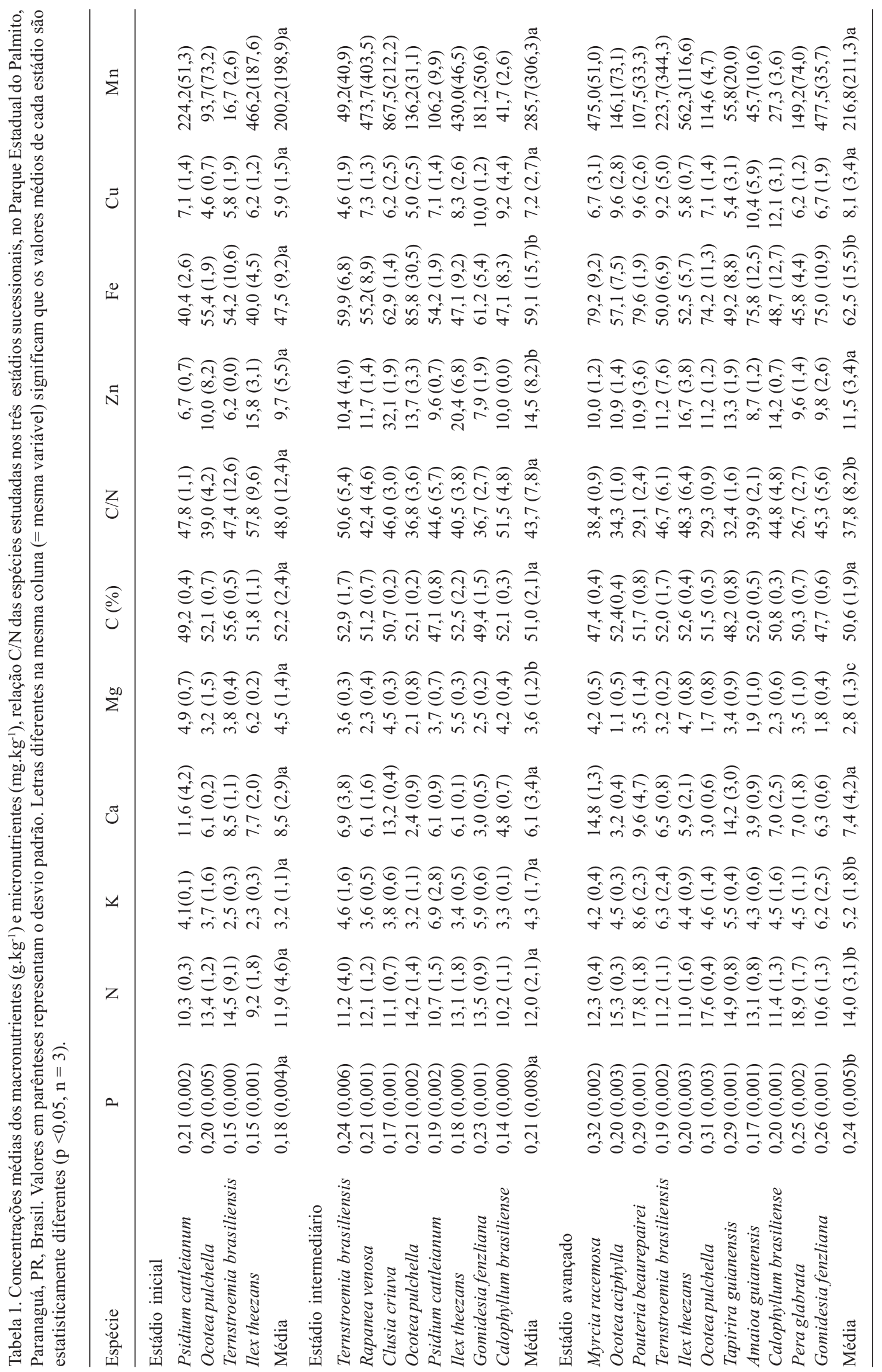


Tabela 2. Comparação das concentrações médias $\left(\mathrm{g} \cdot \mathrm{kg}^{-1}\right)$ dos macronutrientes foliares, por estádio sucessional, com de outras formações florestais tropicais. *Valores máximo e mínimo encontrados.

\begin{tabular}{|c|c|c|c|c|c|c|c|c|}
\hline Autor e data & Tipo de Floresta & Local & $\begin{array}{l}\text { Número } \\
\text { espécie }\end{array}$ & $\mathrm{N}$ & $\mathrm{P}$ & $\mathrm{K}$ & $\mathrm{Ca}$ & $\mathrm{Mg}$ \\
\hline $\begin{array}{l}\text { Este estudo } \\
\quad \text { estádio inicial }\end{array}$ & $\begin{array}{l}\text { Ombrófila Densa das } \\
\text { Terras Baixas }\end{array}$ & Paraná & 4 & 11,8 & 0,18 & 3,2 & 8,5 & 4,5 \\
\hline $\begin{array}{l}\text { Este estudo } \\
\quad \text { estádio intermediário }\end{array}$ & & & 8 & 12,0 & 0,21 & 4,3 & 6,1 & 3,5 \\
\hline $\begin{array}{l}\text { Este estudo } \\
\text { estádio avançado }\end{array}$ & & & 11 & 14,0 & 0,24 & 5,2 & 7,4 & 2,8 \\
\hline Bongers \& Popma 1990 & $\begin{array}{l}\text { Ombrófila Densa das } \\
\text { Terras Baixas }\end{array}$ & México & 68 & 17,4 & 1,33 & 10,5 & - & - \\
\hline Thompson et al. 1992 & $\begin{array}{l}\text { Ombrófila Densa das } \\
\text { Terras Baixas }\end{array}$ & Roraima & 77 & 18,8 & 1,20 & 10,3 & 4,7 & 2,4 \\
\hline \multirow[t]{2}{*}{ Moraes \& Domingos 1997} & $\begin{array}{l}\text { Ombrófila Densa das } \\
\text { Terras Baixas }\end{array}$ & Ilha do Cardoso & o 10 & 31,7 & 1,00 & 10,8 & 10,3 & 4,7 \\
\hline & Restinga & & 10 & 13,0 & 0,60 & 3,5 & 6,3 & 4,0 \\
\hline \multirow[t]{2}{*}{ Britez et al. 19947} & Restinga paludosa & Paraná & 9 & 14,4 & 0,41 & 5,2 & 4,9 & 2,9 \\
\hline & Restinga seca & & 10 & 10,8 & 0,31 & 5,1 & 5,4 & 2,5 \\
\hline Peace \& Macdonald 1981 & Restinga & Malásia & 09 & 8,7 & 0,22 & 3,5 & 7,5 & 2,0 \\
\hline $\begin{array}{l}\text { Reich et al. } 1995 \\
\quad \text { estádio inicial 1-3 anos }\end{array}$ & Tropical úmida & Venezuela & 4 & 16,9 & 0,70 & 3,9 & 3,6 & 1,2 \\
\hline $\begin{array}{l}\text { Reich et al. } 1995 \\
\quad \text { estádio int. }>5 \text { anos }\end{array}$ & & & 2 & 15,5 & 0,60 & 5,1 & 4,1 & 1,7 \\
\hline $\begin{array}{l}\text { Reich et al. } 1995 \\
\quad \text { estádio avanç. > } 60 \text { anos }\end{array}$ & & & 4 & 16,9 & 0,70 & 3,0 & 0,5 & 0,6 \\
\hline Noij et al.1993 & Tropical úmida & geral & - & $6,0-25,0^{*}$ & $0,2-2,0 *$ & $4,0-19,0 *$ & $1,0-2,3^{*}$ & $1,0-9,0 *$ \\
\hline Vitousek \& Sanford 1986 & Tropical úmida & geral & - & $\begin{array}{c}10,2 \\
7,7-12,9)^{*}\end{array}$ & $\begin{array}{c}0,6 \\
(0,2-1,2)^{*}\end{array}$ & $\begin{array}{c}6,0 \\
(3,5-7,2)^{*}\end{array}$ & $\begin{array}{c}6,0 \\
(3,7-10,3)^{*}\end{array}$ & $\begin{array}{c}2,3 \\
(1,4-3,6)^{*}\end{array}$ \\
\hline Herrera \& Finegan 1997 & $\begin{array}{l}\text { Tropical úmida } \\
\text { - secundária }\end{array}$ & Costa Rica & $\begin{array}{l}1 \\
1\end{array}$ & - & $\begin{array}{l}2,10 \\
0,60\end{array}$ & $\begin{array}{r}20,9 \\
3,2\end{array}$ & $\begin{array}{r}14,6 \\
5,2\end{array}$ & $\begin{array}{l}5,7 \\
1,4\end{array}$ \\
\hline Kapelle \& Leal 1996 & Alto-montana, sec. & Costa Rica & 14 & 12,1 & 1,10 & 11,3 & - & - \\
\hline Marin \& Medina 1981 & $\begin{array}{l}\text { Mesófila seca } \\
\text { Esclerófila seca }\end{array}$ & Venezuela & $\begin{array}{l}07 \\
04\end{array}$ & $\begin{array}{l}21,0 \\
11,8\end{array}$ & $\begin{array}{l}1,57 \\
0,70\end{array}$ & - & $\begin{array}{l}13,9 \\
13,9\end{array}$ & - \\
\hline Sobrado \& Medina 1980 & Caatinga & Amazonas & 12 & 8,3 & 0,44 & 8,9 & 3,5 & - \\
\hline
\end{tabular}

apresentado (Tab. 2). O estádio inicial do estudo na Amazônia tem de um a três anos e é esperado que as concentrações de nutrientes foliares em espécies ocorrentes no primeiro ano após o corte e queima sejam maiores do que as concentrações de nutrientes de espécies de estádios mais tardios (Reich et al. 1995) devido a maior disponibilidade de nutrientes após a queima e corte raso do cultivo (no caso, mandioca).

As concentrações médias de $\mathrm{Ca}$ estão entre os maiores valores reportados por Vitousek \& Sanford (1986) e da maioria das demais florestas tropicais (Tab. 2). Altas concentrações de $\mathrm{Ca}$ foram encontradas nas folhas de árvores da várzea e igapós da Amazônia (Klinge et al. 1983; Neves et al. 1999) e nas folhas de espécies arbóreas do estádio inicial de floresta oligotrófica, na Venezuela (Reich et al. 1995). A elevada concentração de Ca nas folhas de algumas espécies (Tab. 1) pode ser resultante da grande quantidade de drusas (cristais de oxalato de cálcio) encontradas nos tecidos foliares (Boeger \& Wisniewski 2003). Estes cristais são interpretados como produto do metabolismo das plantas, cuja função parece estar relacionada com a remoção do cálcio em excesso no sistema (Volk et al. 2002). A quantidade de oxalato de cálcio depositada nas plantas pode ser interpretada como um sub-produto das atividades metabólicas dos fungos que liberam ácido oxálico ou oxalatos no solo (Graustein et al. 1977). A alta concentração de Ca parece estar relacionada com a pouca mobilidade do elemento nos tecidos vegetais e com a longevidade da folha. Espera-se que, quanto mais antiga for a folha, maior seja sua concentração de $\mathrm{Ca}$, pois esse elemento deposita-se nos espessamentos secundários da parede celular na forma de pectatos de cálcio, imobilizandose até ocorrer a queda da folha (Franceschi \& Horner 1980; Binkley 1986; Reich et al. 1995). 
As concentrações médias de Mg estão acima das concentrações reportados por Vitousek \& Sanford (1986), principalmente no estádio inicial. As concentrações médias de Mg são menores no estádio avançado e estas estão próximas às encontradas para outras florestas tropicais (Tab. 2). O Mg pode acumular-se nas paredes celulares secundárias como pectato de $\mathrm{Mg}$, desempenhando função semelhante a do Ca (Babbar \& Ewel 1989). Isso explicaria sua concentração maior nas plantas do estádio sucessional inicial, onde as espécies apresentam maior quantidade de tecidos com paredes secundárias (Boeger \& Wisniewski 2003).

Associada à dinâmica de retenção de $\mathrm{Mg}$ pela vegetação, a alta concentração deste elemento nas folhas parece ser decorrente da concentração elevada no solo, principalmente na parte mais superficial do horizonte Ae nos horizontes orgânicos do estádio inicial. Nos demais estádios, esta concentração diminui nos horizontes orgânicos (Celina Wisniewski, dados não publicados).

As concentrações médias de $\mathrm{K}$ foliares obtidas neste estudo são baixas quando comparadas com as de outras florestas tropicais (Tab. 2). A concentração média de K, no estádio inicial, ficou abaixo das médias reportadas (Vitousek \& Sanford 1986; Noij et al. 1993), sendo o valor semelhante às restingas da Malásia. Entretanto, para o estádio avançado, a concentração média está dentro dos valores reportados e semelhante aos valores encontrados para a restinga da Ilha do Mel (Britez et al. 1997). Os baixos valores de $\mathrm{K}$ podem estar associados com a grande mobilidade do elemento, uma vez que esse não possui função estrutural na planta, acumulando-se no suco vacuolar (Malavolta 1980), o que o torna facilmente lixiviável e de fácil translocação dentro da planta (Mengel \& Kirkby 1987; Binkley 1986). Além disso, a ciclagem do K (planta-solo) é mais rápida do que a dos demais elementos, por se tratar de um cátion monovalente (Jordan 1985). No solo das florestas estudadas, as concentrações médias de K são baixas $(0,004$ a $0,067 \mathrm{cmol}_{\mathrm{c}} \cdot \mathrm{dm}^{-3}$ ) quando comparadas com as de outros espodossolos no Paraná (Britez et al. 1997), havendo maior concentração deste elemento na camada mais superficial do horizonte A $\left(0,06\right.$ a $\left.0,21 \mathrm{cmol} \cdot \mathrm{dm}^{-3}\right) \mathrm{e}$ nos horizontes orgânicos $\left(0,59\right.$ a $1,1 \mathrm{~g}^{\mathrm{kg}} \mathrm{kg}^{-1}$, Celina Wisniewski, dados não publicados), nos três estádios. No solo mineral, as concentrações de K permanecem baixas, enquanto nos horizontes orgânicos ocorre incremento deste elemento ao longo da sucessão $\left(\right.$ estádio inicial $=0,59 \mathrm{~g} \cdot \mathrm{kg}^{-1}$; estádio intermediário $=$
$0,81 \mathrm{~g} \cdot \mathrm{kg}^{-1}$ e estádio avançado $=1,10 \mathrm{~g} \cdot \mathrm{kg}^{-1}$, Celina Wisniewski, dados não publicados), indicando a retenção do mesmo. Conseqüentemente, as maiores concentrações médias de $\mathrm{K}$ nas folhas das espécies analisadas ocorrem nos estádios sucessionais mais avançados.

Apesar das concentrações de $\mathrm{K}$ serem maiores tanto nas folhas quanto nos horizontes orgânicos ao longo do gradiente sucessional, este nutriente ainda encontra-se em baixo suprimento nas áreas estudadas. $\mathrm{O} \mathrm{K}$ no solo e, conseqüentemente, disponível para as plantas, tem origem no intemperismo das rochas. Solos muito intemperizados, arenosos e bem drenados são geralmente pobres em K (Binkley 1986). Nestas condições, o $\mathrm{K}$ disponível para a vegetação é aquele proveniente da liberação da serapilheira que se acumula sobre o solo mineral. Em algumas formações florestais, $89 \%$ do $\mathrm{K}$ total do ecossistema está fixado na vegetação (Golley et al. 1978).

O K é um elemento de alta taxa de absorção, sendo esta dependente da permeabilidade da membrana celular (Marschner 1986). Por outro lado, a absorção do $\mathrm{K}$ e sua posterior retenção na planta é competitivamente afetada pelo $\mathrm{H}, \mathrm{Ca}, \mathrm{Mg}$ e $\mathrm{Na}$ no solo. O K pode ser facilmente reposto por outros cátions, em particular o $\mathrm{Ca}$ e $\mathrm{Mg}$, devido às suas fracas ligações com os argilo-minerais (Mengel \& Kirkby 1987). Estudos em Cordia alliodora, na Costa Rica, mostraram que as altas concentrações de $\mathrm{Mg}$ e $\mathrm{Ca}$, no solo, podem limitar o suprimento de $\mathrm{K}$ para as árvores (Bergmann et al. 1994). O aumento do suprimento de um cátion pode resultar na diminuição da concentração de outros, indicando que a deficiência em K pode ser condicionada pela presença de outros cátions no solo (Mengel \& Kirkby 1987).

Enquanto as concentrações médias de $\mathrm{Ca}$ mantêm-se semelhantes ao longo do processo sucessional, os valores médios para as concentrações de K são maiores nos estádios sucessionais avançados, modificando a relação $\mathrm{K} / \mathrm{Ca}$ foliar. Apesar do aumento da razão $\mathrm{K} / \mathrm{Ca}$, principalmente do estádio inicial $(0,38)$ para o intermediário $(0,89)$, ela ainda é baixa nos três estádios, baseado na razão considerada adequada (2) para as plantas com bom status nutricional (Malavolta 1980). Entretanto, esta "razão adequada" é definida para espécies cultivadas que demandam maior suprimento de nutrientes. Para a Floresta Amazônica, Klinge et al. (1983) encontraram razões de K/Ca que variaram entre 0,2 à 11 para as folhas adultas. As espécies amazônicas estudadas por Neves et al. (1999) apresentaram razões entre 0,6 e 1 . A relação $\mathrm{K} / \mathrm{Mg}$ 
(estádio inicial $=0,7$, intermediário $=1,21$ e avançado $=$ $1,84)$ apresenta comportamento similar à da relação $\mathrm{K} / \mathrm{Ca}$.

Apesar das razões $\mathrm{K} / \mathrm{Ca}$ e $\mathrm{K} / \mathrm{Mg}$ nos estádios estudados serem baixas $(<1)$, existem variações entre as espécies de cada estádio. No estádio inicial, $O$. pulchella é a única espécie com uma razão $\mathrm{K} / \mathrm{Mg}>1$. No estádio intermediário, a situação inverte-se, onde apenas três espécies apresentam relação $<1, C$. criuva $(0,84)$, I. theezans $(0,61) \mathrm{e}$ C. brasiliense $(0,78)$. No estádio avançado, apenas I. theezans apresenta relação $\mathrm{K} / \mathrm{Mg}<1$. Para a razão $\mathrm{K} / \mathrm{Ca}$, apenas $P$. cattleianum $(1,13)$ e G. fenzliana $(1,96)$, no estádio intermediário e $O$. aciphylla $(1,40)$, $O$. pulchella $(1,53)$ e A. guianensis $(1,10)$, no estádio avançado apresentaram uma relação $>1$. As variações nas razões de $\mathrm{K} / \mathrm{Ca}$ e $\mathrm{K} / \mathrm{Mg}$ evidenciam o comportamento diferenciado das espécies frente ao processo de absorção, metabolismo e perdas de nutrientes na planta (Ernest 1975; Breemen 1995). Golley et al. (1980) mostraram que espécies de certas famílias concentram ou discriminam os elementos individualmente, exibindo padrões diferentes nas concentrações dos nutrientes. Entretanto, não se tem, ainda, dados suficientes para identificar e estabelecer as relações entre nutrientes e determinadas famílias vegetais.

A concentração relativa dos macronutrientes nas folhas das espécies estudadas deu-se da seguinte maneira: $\mathrm{Ca}>\mathrm{N}>\mathrm{Mg}>\mathrm{K}>\mathrm{P}$, para o estádio inicial e $\mathrm{N}>\mathrm{Ca}>\mathrm{K}>\mathrm{Mg}>\mathrm{P}$, para os estádios intermediário e avançado. Estas relações demonstraram o aumento da concentração média foliar de $\mathrm{K}$ e diminuição de $\mathrm{Ca}$ e Mg a partir do estádio intermediário. Concentrações relativas semelhantes aos dos estádios intermediário e avançado foram encontradas para as florestas tropicais úmidas estudadas por Golley et al. (1978). Nas restingas do Paraná (Britez et al. 1997) e nas florestas tropicais maduras sobre espodossolos (Thompson et al. 1992) a distribuição destes nutrientes é $\mathrm{N}>\mathrm{K}>\mathrm{Ca}>$ $\mathrm{Mg}>\mathrm{P}$, sugerindo maior suprimento de $\mathrm{K}$ nestas florestas.

A relação $\mathrm{C} / \mathrm{N}$, nas folhas, é estatisticamente diferente no estádio avançado em relação aos demais $(\mathrm{p}<0,05)$ e tende a diminuir à medida que a sucessão avança (Tab. 1). Esta diminuição foi observada nos horizontes orgânicos (Celina Wisniewski, dados não publicados). Entretanto, apesar de ocorrer uma redução da relação $\mathrm{C} / \mathrm{N}$ ao longo da sucessão, esta relação ainda é alta (>25:1, Tab. 1). A relação $\mathrm{C} / \mathrm{N}$ foliar está intimamente ligada ao material estrutural, representado pelo teor de lignina, celulose e gorduras (Haag 1985; Perry 1994). As maiores concentrações de carbono nos estádios mais jovens podem estar relacionadas com a maior presença de espécies com características escleromorfas, que são ricas em material estrutural (Boeger \& Wisniewski 2003).

Entre os micronutrientes, o elemento que apresentou a maior variação de concentração na folha foi o Mn, nos três estádios sucessionais (inicial $=99,4 \%$; intermediário $=107,2 \%$ e avançado $=97,4 \%$ ). As concentrações médias de $\mathrm{Fe}$ e $\mathrm{Zn}$ apresentaram diferenças significativas entre os estádios sucessionais $(\mathrm{p}<0,05)$. A concentração média de $\mathrm{Fe}$ do estádio inicial é menor dos demais estádios e a concentração média de $\mathrm{Zn}$ no estádio intermediário é menor dos demais estádios. Para o Cu e Mn não foram observadas diferenças significativas $(p>0,05)$ entre os três estádios (Tab. 1).

As concentrações médias de micronutrientes encontradas neste estudo estão dentro dos valores máximo e mínimo encontrados por Drechsel \& Zech (1991), sendo que as concentrações de Zn no estádio inicial encontram-se próximas aos valores inferiores reportados por estes autores (Tab. 3). Entretanto, todas as concentrações médias de micronutrientes analisadas tenderam ser menores neste estádio. Para $\mathrm{Fe}$ e $\mathrm{Cu}$, os valores médios dos estádios intermediário e avançado são próximos daqueles encontrados nas plantas de restingas do Paraná e Ilha do Cardoso, em São Paulo (Britez et al. 1997; Moraes \& Domingos 1997), mas são inferiores aos encontrados para a Amazônia (Stark 1970; Golley et al. 1978), floresta tropical da Costa Rica (Herrera \& Finegan 1997) e floresta ombrófila mista (Reissmann et al. 1983) (Tab. 3). As concentrações médias de $\mathrm{Zn}$ são baixas para todos os estádios e, conseqüentemente, para todas as espécies. Concentrações baixas de $\mathrm{Zn}$ nas folhas também foram encontradas para espécies de restinga (Britez et al. 1997), para espécies da Amazônia (Neves et al. 1999) e Costa Rica (Herrera \& Finegan 1997). Uma das possíveis causas das baixas concentrações de Zn nas folhas das espécies estudadas é a baixa concentração deste nutriente no solo (Britez et al. 1997), que está relacionado com o material de origem (Mengel \& Kirkby 1987).

Adicionalmente, as perdas de $\mathrm{Zn}$ no solo também podem ocorrer devido à lixiviação do solo, em meio ácido, que é muito ativa na mobilização deste nutriente. Isto ocorre, principalmente, em certos horizontes de solos arenosos, como os espodossolos (Kabata-Pendias \& Pendias 1984). Além disso, este elemento também 
Tabela 3. Comparação das concentrações médias $\left(\mathrm{mg} \cdot \mathrm{g}^{-1}\right)$ dos micronutrientes foliares, por estádio sucessional, com de outras formações florestais tropicais maduras ou secundárias. * Valores mínimo e máximo encontrados para as 37 espécies analisadas.

\begin{tabular}{|c|c|c|c|c|c|c|c|}
\hline Autor e data & Tipo de Floresta & Local & $\begin{array}{l}\text { Número } \\
\text { espécie }\end{array}$ & $\mathrm{Zn}$ & $\mathrm{Fe}$ & $\mathrm{Cu}$ & $\mathrm{Mn}$ \\
\hline $\begin{array}{l}\text { Este estudo } \\
\quad \text { - estádio inicial }\end{array}$ & $\begin{array}{l}\text { Ombrófila Densa das } \\
\text { Terras Baixas }\end{array}$ & Paraná & 4 & 9,7 & 47,5 & 5,9 & 200,2 \\
\hline $\begin{array}{l}\text { Este estudo } \\
\quad \text { - estádio intermediário }\end{array}$ & & & 8 & 14,5 & 59,1 & 7,2 & 285,7 \\
\hline $\begin{array}{l}\text { Este estudo } \\
\text { - estádio avançado }\end{array}$ & & & 11 & 11,5 & 62,5 & 8,1 & 216,8 \\
\hline \multirow[t]{2}{*}{ Moraes e Domingos 1997} & $\begin{array}{l}\text { Ombrófila Densa das } \\
\text { Terras Baixas - madura }\end{array}$ & São Paulo & 10 & 39,0 & 143,0 & 13,0 & $1.494,0$ \\
\hline & Restinga - madura & & 10 & 24,0 & 101,0 & 6,0 & 196,0 \\
\hline \multirow[t]{2}{*}{ Britez et al. 1997} & Restinga paludosa - madura & Paraná & 9 & 13,0 & 63,0 & 6,9 & 89,0 \\
\hline & Restinga seca - madura & & 10 & 19,0 & 55,0 & 8,5 & 197,0 \\
\hline \multirow[t]{2}{*}{ Golley et al. 1978} & Tropical Úmida - secundária & Amazônia & - & 31,0 & 193,0 & 13,0 & 174,0 \\
\hline & Tropical Úmida - madura & & - & 27,0 & 176,0 & 8,0 & 63,0 \\
\hline \multirow[t]{2}{*}{ Herrera \& Finegan 1997} & Tropical úmida - secundária & Costa Rica & 1 & 33,0 & - & 19,0 & 29,0 \\
\hline & & & 1 & 6,0 & - & 8,0 & 326,0 \\
\hline \multirow[t]{2}{*}{ Stark 1970} & Tropical/solos arenosos - secundária & Amazônia & - & - & 47,5 & 10,0 & 6,2 \\
\hline & Tropical/solos arenosos - madura & & - & - & 74,2 & 13,1 & 11,4 \\
\hline Drechsel \& Zech 1991 & Tropical - madura & geral & 37 & $9-101 *$ & $27-1.310^{*}$ & $2-49 *$ & $22-4.000 *$ \\
\hline Reissmann et al. 1983 & Ombrófila Mista - madura & Paraná & - & 29 & 103,5 & 22,2 & $1.968,7$ \\
\hline
\end{tabular}

pode formar complexos quelatados com a matéria orgânica, tornando-se não disponível para as plantas (Malavolta 1980; Kabata-Pendias \& Pendias 1984). Apesar de não ter sido feita a análise de micronutrientes para os solos das áreas estudadas, espodossolos de restinga da Ilha do Mel, PR, próximos ao local de estudo, também apresentaram baixas concentrações de Zn (Britez et al. 1997).

O Mn apresenta um comportamento diferente dos demais elementos. Os valores médios são elevados e existe uma grande variação entre as espécies e entre os indivíduos analisados, conforme se observa no desvio padrão de cada espécie (Tab. 1) e no coeficiente de variação de cada estádio. Isto pode também estar relacionado com a disponibilidade de Mn no solo, pois este nutriente na forma divalente é relativamente móvel e pode ser facilmente lixiviado, o que acontece freqüentemente em solos ácidos (Scheffer \& Schachtschabel 1973; Mengel \& Kirkby 1987). Porém, a comprovação desta hipótese requer um estudo da dinâmica das diferentes formas de $\mathrm{Mn}$ nestes solos, em especial.

As concentrações de Mn obtidas neste estudo são maiores quando comparados com outras formações vegetais (Tab. 3), com exceção da floresta ombrófila mista no Paraná (Reissmann et al. 1983) e com os valores máximos para outras florestas tropicais listadas por Dreshsel \& Zech (1991) (Tab. 3). Entretanto, as concentrações de Mn também variam entre as diferentes espécies de restingas (Britez et al. 1997), florestas tropicais (Herrera \& Finegan 1997) (Tab. 3) e para espécies de diferentes famílias botânicas (Stark 1970). O Mn é considerado um dos elementos de maior acumulação em determinadas espécies e famílias (Rodin \& Bazilivic 1967). Neves et al. (1999) também encontraram diferenças significativas entre as concentrações médias foliares de Mn para Virola surinamensis e Ceiba pentandra. Isto indica que as espécies possuem diferenças nas exigências para este nutriente e na capacidade de sua absorção pelas raízes (Britez et al. 1997; Neves et al. 1999).

As relações $\mathrm{Fe} / \mathrm{Mn}$ e $\mathrm{Zn} / \mathrm{Cu}$ têm comportamentos distintos ao longo dos estádios sucessionais estudados. A razão $\mathrm{Fe} / \mathrm{Mn}$ tende a diminuir principalmente entre o estádio inicial $(1,15)$ e intermediário $(0,64)$. Entretanto, a razão no estádio inicial é alta $(1,0)$ quando se consideram os valores médios de todas as espécies estudadas. Geralmente para as espécies florestais, tanto coníferas como latifoliadas, prevalece razão $\mathrm{Fe} / \mathrm{Mn}<1$ (Neves et al. 1999). Quando se exclui da análise as concentrações médias de $T$. brasiliensis, cuja razão média é 3,2 devido às altas concentrações de $\mathrm{Fe}$, a razão do estádio sucessional inicial diminui para 0,3 , invertendo a tendência da razão $\mathrm{Fe} / \mathrm{Mn}$ ao longo da sucessão. Ternstroemia brasiliensis é a espécie com menor concentração de Mn tanto no estádio inicial como no 
intermediário, o que mantém, para estes dois estádios uma razão $\mathrm{Fe} / \mathrm{Mn}>1$. A concentração de $\mathrm{Mn}$ das folhas de T. brasiliensis é maior no estádio avançado, modificando a razão $\mathrm{Fe} / \mathrm{Mn}$ (Tab. 1).

A relação $\mathrm{Zn} / \mathrm{Cu}$ aumentou do estádio inicial $(1,7)$ para o intermediário $(2,2)$, diminuindo do intermediário para o avançado $(1,5)$. Ocorrem exceções no estádio inicial para $P$. catteianum, no estádio intermediário para G. fenzliana e no estádio avançado para A. guianensis, cujas razões são $<1$ (Tab. 1). Segundo Malavolta (1980), a razão adequada $\mathrm{Zn} / \mathrm{Cu}$ é em torno de 3. Apesar do aumento das concentrações médias de $\mathrm{Zn}$ ao longo dos estádios sucessionais, a relação $\mathrm{Zn} / \mathrm{Cu}$ ainda mantém-se baixa, porque as concentrações médias de $\mathrm{Zn}$ são baixas e ocorre também um aumento nas concentrações médias de $\mathrm{Cu}$ de um estádio para o outro.

Para os três estádios, a distribuição de micronutrientes deu-se da seguinte maneira: $\mathrm{Mn}>\mathrm{Fe}>\mathrm{Zn}$ $>\mathrm{Cu}$. Esta distribuição também foi encontrada por Ernest (1975), Golley et al. (1980) e Britez et al. (1997) para outras florestas tropicais.

A análise das concentrações médias dos nutrientes por espécie que ocorrem em mais de um estádio sucessional indica que algumas espécies não apresentam o mesmo gradiente de concentração dos nutrientes encontrado para os estádios (Tab. 1). O valor médio da concentração de $\mathrm{P}$ para $P$. cattleianum no estádio inicial é maior que o do estádio intermediário, ocorrendo o mesmo entre os valores médios de T. brasiliensis entre o estádio intermediário e avançado. Para o N, o valor médio de T. brasiliensis é maior no estádio inicial do que o intermediário, enquanto que para $I$. theezans e G. fenzliana os valores médios são maiores no estádio intermediário do que no avançado. Para o $\mathrm{Zn}$, os valores médios de $G$. fenzliana e $C$. brasiliense no estádio intermediário foram maiores que no estádio avançado enquanto que os valores médios da concentração de $\mathrm{Fe}$ de T. brasiliensis e $O$. pulchella, no estádio intermediário são menores que no estádio avançado.

Para detectar se estes padrões diferenciados apresentavam alguma significância, realizou-se a análise de variância (ANOVA) de cada nutriente, por espécie e estádio sucessional. Apenas duas espécies apresentaram diferenças significativas $(p<0,05)$ entre os estádios intermediário e avançado: concentração média de $\mathrm{N}$ de $G$. fenzliana e concentração média de $\mathrm{Zn}$ de C. brasiliense. Para as demais espécies, as diferenças não foram estatisticamente significantes $(\mathrm{p}>0,05)$.
O padrão da concentração de nutrientes foliares de algumas espécies ao longo do gradiente sucessional parece ocorrer em função do requerimento diferenciado de nutrientes para cada espécie. Estudos em sistemas agroflorestais mostraram que Cordia alliodora apresentou maior demanda de macronutrientes do que Vochysia ferruginea, indicando que $V$. ferruginea aparentemente apresenta crescimento mais rápido em solos inférteis do que $C$. alliodora (Herrera \& Finegan 1997). Isto também parece ocorrer ao longo do gradiente sucessional, pois as diferenças ambientais de cada estádio poderão resultar em diferentes disponibilidades de recursos durante o processo sucessional associado às características intrínsecas de cada espécie, o que implicaria na seleção de características durante as diferentes fases da sucessão (Reich et al. 1995; Guariguata \& Ostertag 2001).

As maiores concentrações médias de alguns macro $(\mathrm{N}, \mathrm{P}, \mathrm{K})$ e micronutrientes $(\mathrm{Fe}, \mathrm{Zn})$ nos estádios intermediário e avançado em relação ao estádio inicial podem ser explicados parcialmente pelo incremento da espessura dos horizontes orgânicos e da produção de serapilheira (Celina Wisniewski, dados não publicados) o que resulta numa maior disponibilidade de nutrientes para a vegetação (Jordan 1985; Perry 1994; Rode 1995). O aumento da espessura do horizonte orgânico é expressivo entre o estádio inicial e o avançado, como comentado anteriormente, assim como o aumento na produção de serapilheira, não havendo diferenças significativas entre a produção de serapilheira do estádio intermediário e avançado (Celina Wisniewski, dados não publicados).

No estádio inicial, a serapilheira acumulada sobre o solo apresenta-se descontínua, com áreas onde esta se encontra ausente, ficando o solo mineral totalmente exposto (Celina Wisniewski, observação pessoal). As características da serapilheira facilitam a lixiviação do solo com conseqüente perda de nutrientes. Além disso, no estádio inicial, o estrato arbóreo é menos denso, o que acarreta em maiores temperaturas e menor umidade relativa do ar e do solo. Sob estas condições, a decomposição é mais lenta, interferindo assim na liberação dos nutrientes (Britez et al. 1997). Nos estádios intermediário e avançado, a serapilheira acumulada é mais espessa e proporciona meio mais adequado para a retenção de água e para os processos de decomposição. Nos horizontes orgânicos, ocorre uma série de reações complexas, associadas à natureza do material a ser decomposto (por exemplo, conteúdo de lignina, celulose e compostos fenólicos das folhas) o que interfere diretamente na taxa de liberação dos 
nutrientes (Haag 1985; Vitousek \& Sanford 1986). A taxa de decomposição obtida para as florestas estudadas, expressa pelo coeficiente de decomposição $(\mathrm{K})$, foi mais rápida no estádio avançado $(\mathrm{K}=0,45)$ em relação aos demais estádios (inicial: $\mathrm{K}=0,40 \mathrm{e}$ intermediário: $\mathrm{K}=0,38$ ), o que indica retorno mais rápido dos nutrientes no estádio avançado (Celina Wisniewski, dados não publicados). Nos estádios mais avançados da sucessão, as árvores também se encontram mais desenvolvidas e há a formação de vários estratos do dossel, o que diminui a intensidade luminosa, resultando em menor temperatura e maior umidade atmosférica no interior da floresta.

Os dados aqui apresentados suportam a hipótese de que as concentrações médias de determinados nutrientes variam entre os estádios sucessionais da floresta ombrófila densa estudada. As concentrações médias de N, P, K, Fe e Zn diferem entre os estádios, com incremento à medida que o processo sucessional avança, enquanto que as concentrações médias de $\mathrm{Mg}$ diminuem. As concentrações médias de $\mathrm{Ca}, \mathrm{C}, \mathrm{Cu}$ e $\mathrm{Mn}$ não apresentaram diferenças significantes entre os estádios. As diferenças obtidas entre as concentrações médias dos nutrientes nos estádios sucessionais estão relacionadas, parcialmente, com a produção da serapilheira e da composição química dos horizontes orgânicos diferenciadas entre os estádios, além das alterações na estrutura do dossel da floresta.

Estes dados também corroboram a hipótese de que ocorre um incremento na concentração de nutrientes na biomassa durante o processo de sucessão (Peet 1992), como conseqüência da disponibilidade destes no solo. O solo, juntamente com a luz é um dos fatores abióticos de maior importância para o crescimento e a definição da composição florística das espécies nos primeiros estádios da sucessão secundária. As mudanças drásticas nas propriedades do solo como a perda da matéria orgânica altera os agregados do solo, que, por sua vez, interfere na capacidade de retenção de água no solo (Cromack 1981). Além disso, a matéria orgânica influencia na fertilidade do solo, retendo formas orgânicas de nutrientes e na capacidade de troca iônica, que facilita a absorção de nutrientes, permitindo que cátions adsorvidos ao solo ou a matéria orgânica sejam facilmente substituídos por outros cátions em solução (Brady 1990; Guariguata \& Ostertag 2001).

Apesar de ser difícil prever os padrões de reposição de uma floresta, os estudos indicam que existe uma seqüência de eventos e processos que ocorrem durante a sucessão secundária, especialmente para a ciclagem de nutrientes (Brown \& Lugo 1990; Peet 1992). De maneira geral, as florestas secundárias tendem a acumular rapidamente nutrientes nas folhas e raízes nos estádios iniciais da sucessão, assim como o retorno ocorre mais rápido nestes estádios (GómezPompa \& Vázquez-Yanes 1974). Nos estádios mais tardios, o retorno de nutrientes tende a ser mais lento, porque a maioria da biomassa fica alocada na madeira (Peet 1992). Porém, é importante ressaltar que a recomposição do solo em termos de nutrientes depende do tipo de floresta e de solo, além do tipo e intensidade da atividade do uso da área (Harcombe 1977; Kapelle et al. 1995). Vários estudos indicam que a dominância de espécies de um determinado estádio pode ser alterada pela disponibilidade de nutrientes e as espécies de estádios anteriores podem alterar a disponibilidade de recursos para outras espécies, afetando a trajetória sucessional (Rode 1993; Herrera \& Finegan 1997; Guariguata \& Ostertag 2001).

Frente ao esparso conhecimento sobre as relações planta e solo, em diferentes estádios sucessionais, estudos adicionais são necessários para contribuir com o entendimento dos processos de regeneração das florestas tropicais e assim fornecer subsídios para o manejo e conservação adequada destes ecossistemas.

\section{Agradecimentos}

Os autores agradecem ao BANESTADO S.A. Reflorestadora, pela permissão do uso da área; ao Sr. Nathanael do Rosário, pelo auxílio no trabalho de campo; ao técnico de laboratório Sr. Aldair Munhoz, pelo auxílio nas análises químicas dos nutrientes; ao Prof. Paulo Guimarães, pelo auxílio na análise estatística; ao Dr. Delane Kritsky, pela revisão do Abstract.

\section{Referências bibliográficas}

Aerts, R. \& Chapin III, F.S. 2000. The mineral nutrition of wild plants revisited: re-evaluation of processes and patterns. Pp. 1-67. In: A.H. Fitter \& D.G. Raffaelli (eds.). Advances in Ecological Research. v.30. San Diego, Academic Press.

Babbar, L.I. \& Ewel, J.J. 1989. Decomposición del foliage en diversos ecosistemas sucesionales tropicales. Biotropica 21(1): 20-29.

Bergmann, C.; Sturmann, M. \& Zech, W. 1994. Site factors, foliar nutrient levels and growth of Cordia alliodora plantations in the humid lowlands of Northern Costa Rica. Plant and Soil 166: 193-202. 
Binkley, D. 1986. Forest nutrition management. A WileyInterscience Publication. New York, John Wiley \& Sons.

Boeger, M.R.T.; Negrelle, R.R.B. \& Martins, R. 2000. Produção de serapilheira num gradiente sucessional em floresta ombrófila densa das terras baixas, Município de Itapoá, SC. Tecnologia e Ambiente 6(2): 91-106.

Boeger, M.R.T. \& Wisniewski, C. 2003. Comparação da morfologia foliar de espécies arbóreas de três estádios sucessionais distintos de floresta ombrófila densa (Floresta Atlântica) no Sul do Brasil. Revista Brasileira de Botânica 26(1): 61-72.

Bongers, F. \& Popma, J. 1990. Leaf characteristics of the tropical rain forest flora of Los Tuxtlas, Mexico. Botanical Gazette 151(3): 354-365.

Brady, N.C. 1990. The nature and properties of soils. New York, Macmillan.

Breemen, N. van. 1995. Nutrient cycling strategies. Plant and Soil 168/169: 321-326.

Britez, R.M.; Reissmann, C.B.; Silva, S.M. \& Santos Filho, A. 1992. Deposição estacional de serapilheira e macronutrientes em uma floresta de Araucaria em São Mateus do Sul-Paraná. Revista do Instituto Florestal de São Paulo 4(1): 766-772.

Britez, R.M.; Reissmann, C.B.; Silva, S.M.; Athayde, S.F.; Lima, R.X.B. \& De Quadros, R.M. 1997. Chemical characterization of two forests on the coastal plains of the Ilha do Mel, Paraná, Brazil. Developments in Plants and Soil Sciences 78: 461-462.

Brown, S. \& Lugo, A.E. 1990. Tropical secondary forests. Journal of Tropical Ecology 6: 1-32.

Chandrashekara, U.M. \& Ramakrishnan, P.S. 1994. Successional patterns and gap phase dynamics of a humid tropical forest of the Western Ghats of Kerala, India: ground vegetation, biomass, productivity and nutrient cycling. Forest Ecology and Management 70(1-3): 23-40.

Chapin III, F.S. 1980. The mineral nutrition of wild plants. Annual Review of Ecology and Systematics 11: 233-240.

Chinea, J.D. 2002. Tropical forest succession on abandoned farms in the Humacao Municipality of eastern Puerto Rico. Forest Ecology and Management 167(1-3): 195-207.

Cromack Jr., K. 1974. Below-ground processes in forest succession. Pp. 361-373. In: D.C. West; H.H. Shugart \& D.B. Botkin (eds.). Forest succession: concepts and application. New York, Springer-Verlag.

Cunha, G.C.; Grendene, L.A.; Durlo, M.A.; Dressan, D.A. 1993. Dinâmica nutricional em floresta estacional decidual com ênfase aos minerais provenientes da deposição de serapilheira. Ciência Florestal 3(1): 35-64.

Domingos, M.; Moraes, R.M.; De Vuono, Y.S. \& Anselmo, C.E. 1997. Produção de serapilheira retorno de nutrientes em um trecho de Mata Atlântica secundária na Reserva Biológica de Paranapiacaba, SP. Revista Brasileira de Botânica 20(1): 91-96.

Drechsel, P. \& Zech, W. 1991. Foliar nutrient levels of broadleaved tropical trees: a tabular review. Plant and Soil 131: 29-46.

EMBRAPA - Empresa Brasileira de Pesquisa AgropecuáriaSNLCS. 1984. Levantamento de reconhecimento dos solos do estado do Paraná. Curitiba, EMBRAPA SNLCS/ SUDESUL/IAPAR. v.2.
EMBRAPA - Empresa Brasileira de Pesquisa Agropecuária. 1979. Manual de métodos de análise de solo. Rio de Janeiro, Centro Nacional de Pesquisa de Solos.

Ernest, W. 1975. Variation in the mineral contents of leaves of trees in Miombo Woodland in South Central Africa. Journal of Ecology 61: 801-807.

Franceschi, V.R. \& Horner Jr., H.T. 1980. Calcium oxalate crystals in plants. The Botanical Review 46(4): 361-427.

Golley, F.B.; McGinnis, J.T.; Clements, R.G.; Child, G.I. \& Duever, M.J. 1978. Ciclagem de minerais em um ecossistema de floresta tropical úmida. São Paulo, EPU/EDUSP.

Golley, F.B.; Yantko, J.; Richardson, T. \& Klinge, H. 1980. Biogeochemistry of tropical forests: 1. The frequency distribution and mean concentration of selected elements in a forest near Manaus, Brazil. Tropical Ecology 21(1): 59-70.

Gómez-Pompa, A. \& Vasquez-Yanes, C. 1974. Studies on the secondary succession of tropical lowlands: the life cycle of secundary species. Pp. 336-342. In: D.C. West; H.H. Shugart \& D.B. Botkin (eds.). Forest succession: concepts and application. New York, Springer-Verlag.

Graustein, W.C.; Cromack Jr., K. \& Sollins, P. 1977. Calcium oxalate: occurrence in soils and effect on nutrient and geochemical cycles. Science 198(4323): 1252-1254.

Grubb, P.J. 1977. Control of forest growth and distribution on wet tropical mountains: with special reference to mineral nutrition. Annual Review of Ecology and Systematics 8: 83-107.

Guariguata, M.R. \& Ostertag, R. 2001. Neotropical secondary forest sucession: changes in structural and functional characteristics. Forest Ecology and Management 148: 185-206.

Haag, P.H. (ed.). 1985. Ciclagem de nutrientes em Florestas Tropicais. Campinas, Fundação Cargill.

Harcombe, P.A. 1977. The influence of fertilization on some aspects of succession in a humid tropical forest. Ecology 58(6): 1375-1383.

Herrera, B. \& Finegan, B. 1997. Substrate conditions, foliar nutrients and the distributions of two canopy tree species in a Costa Rican secondary rain forest. Plant and Soil 191: 259-267.

Hildebrand, C.; Hildebrand, E.E. \& Reissmann, C.B. 1977. Manual de análise química de solo e planta. Curitiba, Departamento de Solos, Universidade Federal do Paraná.

IAPAR - Instituto Agronômico do Paraná. 1994. Cartas climáticas do Estado do Paraná. Documento 18. Londrina, PR.

Johnson, C.M.; Vieira, I.C.G.; Zarin, D.J.; Frizano, J. \& Johnson, A.H. 2001. Carbon and nutrient storage in primary and secondary forests in eastern Amazônia. Forest Ecology and Management 147(2-3): 245-252.

Jones Jr., J.B. \& Case, V.W. 1990. Sampling, Handling, and Analyzing Plant Tissue Samples. Pp. 389-427. In: R.L. Westerman; J.V. Baird; N.W. Christensen; P.E. Fixen \& D.A. Whitney. Soil testing and plant analysis. Madison, Soil Science Society of America Inc.

Jordan, C.F. 1985. Nutrient cycling in Tropical Forest Ecosystems. Chichester, John Wiley \& Sons. 
Kabata-Pendias, A. \& Pendias, H. 1984. Trace elements in soil and plants. Boca Raton, CRC Press.

Kapelle, M. \& Leal, M.E. 1996. Changes in leaf morphology and foliar nutrient status along a successional gradient in a Costa Rican upper montane Quercus forest. Biotropica 28(3): 331-344.

Kappelle, M.; Kennis, P.A.F. \& Vries, R.A.J. 1995. Changes in diversity along a successional gradient in a Costa Rican upper montane Quercus forest. Biodiversity and Conservation 4: 10-34.

Kellman, M.C. 1969. Some environmental components of shifting cultivation in upland Mindanao. Journal of Tropical Geography 28: 40-56.

Klinge, H.; Furch, K.; Harms, E. \& Revilla, J. 1983. Foliar nutrient levels of native tree species from Central Amazonia. I. Inundation forests. Amazoniana 8(1): 19-45.

Klinge, H. 1985. Foliar nutrient levels of native tree species from Central Amazônia. 2. Campina. Amazoniana 9(3): 281-295.

Maack, R. 1981. Geografia Física do estado do Paraná. Curitiba, Livraria José Olympio Editora. Co-Edição com a Secretaria da Cultura e do Esporte do Estado do Paraná.

Magalhães, L.M.S. \& Blum, W.E.H. 1999. Concentration and distribution of nutrients in leaves of forest species, in eastern Amazonia. Floresta e Ambiente 6(1): 127-137.

Malavolta. E. 1980. Elementos de nutrição mineral de plantas. São Paulo, Editora Agronômica Ceres Ltda.

Malavolta, E.; Vitti, G.C. \& Oliveira, S.A. 1989. Avaliação do Estado Nutricional das Plantas - Princípios e Aplicações. Piracicaba, Associação Brasileira para a Pesquisa da Potassa e do Fosfato.

Marin, D. \& Medina, E. 1981. Duracion foliar, contenido de nutrientes y esclerofilia en arboles de un bosque muy seco tropical. Acta Cientifica Venezolana 32: 508-514.

Marschner, H. 1986. Mineral nutrition of higher plants. London, Academic Press \& Harcourt Brace \& Company, Publishers.

Martins, C.C. \& Rodrigues, R.R. 1999. Produção de serapilheira em clareiras de uma floresta estacional semidecidual no município de Campinas, SP. Revista Brasileira de Botânica 22(3): 405-412.

Medina, E.; Garcia, V. \& Cuevas, E. 1990. Sclerophylly and oligotrophic environments: relationships between leaf, structure, mineral nutrient content, and drought resistance in tropical rain forest of the upper Rio Negro region. Biotropica 22(1): 51-64.

Meguro, M.; Vinueza, G.N. \& Delitti, W.B.C. 1979. Ciclagem de nutrientes na mata mesófila secundária, São Paulo. I. Produção e conteúdo de nutrientes minerais no folhedo. Boletim de Botânica 7: 11-31.

Meguro, M. \& Delitti, W.B.C. 1985. O papel da precipitação na ciclagem de nutrientes minerais no campo cerrado de Mogi-Guaçu, SP. Ciência e Cultura 37(suplemento): 501-504.

Mello, R.S.P. \& Porto, M.L. 1997. Produção de serapilheira em duas florestas subtropicais no Sul do Brasil. Iheringia, ser. Botanica 49: 63-85.

Mengel, K. \& Kirkby, E.A. 1987. Principles of plant nutrition. Worblaufen-Bern, International Potash Institute.
Moraes, R.M. \& Domingos, M. 1997. Elementos minerais em folhas de espécies arbóreas de Mata Atlântica e Mata de Restinga, na Ilha do Cardoso, SP. Revista Brasileira de Botânica 20(2): 133-138.

Moraes, R.M.; Delitti, W.B.C. \& De Vuono, Y.S. 1999. Litterfall and litter nutrient content in two brazilian tropical forests. Revista Brasileira de Botânica 22(1): 9-16.

Muoghalu, J.L. 2003. Contributions of throughfall, stemflow and litterfall to nutrient cycling in a secondary lowland rain forest in Ile-Ife, Nigeria. Journal of Tropical Forest Science 15(3): 399-410.

Neves, E.J.M; Reissmann, C.B.; Ferreira, C.A.; Bellote, A.F.J. \& Dünisch, O. 1999. Nutricional status of Ceiba pentandra (L.) Gaertn and Virola surinamensis (Rol.) Warb growing no poor soils in the Brazilian Amazon Region. Pp. 71-77. In: J. Bauch; O. Dünisch \& L. Gasparatto (eds.). Investigations on tree species suitable for the recultivation of degraded land areas in central Amazonia. Hamburg, Mitteilkungen der Dbundesforschungsanstalt für Forst- und Holzwirtschaft.

Niinemets, Ü. \& Kull, K. 2003. Leaf structure vs. nutrient relationships vary with soils conditions in temperate shrubs and trees. Acta Oecologica 24: 209-219.

Noij, J.G.A.M.; Jansen, B.H.; Wesselink, L.G. \& Van Grinsren, J.J.M. 1993. Modeling nutrient and moisture cycling in tropical forests. The Netherlands, Tropenbos Series 4 Wargeningen.

Parolin, P.; Armbrüster, N. \& Junk, W.J. 2002. Seasonal changes of leaf nitrogen content in trees of Amazonian floodplains. Acta Amazônica 32(2): 231-240.

Peace W.J.H. \& Macdonald, F.D. 1981. An investigation of the leaf anatomy, foliar mineral levels, and water relations of tress of a Sarawak Forest. Biotropica 13(2): 100-109.

Peet, R.K. 1992. Community structure and ecosystem function. Pp. 103-151. In: D.C. Glenn-Lewin; R.K. Peet \& T.T. Veblen (eds.). Plant Succession: theory and prediction. London, Chapman \& Hall.

Perry, D.A. 1994. Forest ecosystems. Baltimore, The Johns Hopkins University Press.

Reich, P.B.; Ellsworth, D.S. \& Uhl, C. 1995. Leaf carbon and nutrient assimilation and conservation in species of different successional status in an oligotrophic Amazonian forest. Functional Ecology 9: 65-76.

Reissmann, C.B.; Rocha, H.O.; Koehler, C.W.; Caldas, R.L.S. \& Hildebrand, E.E. 1983. Bio-elementos em folhas e hastes de erva-mate (Ilex paraguariensis St. Hill.) sobre cambissolos na região de Mandirituba-PR. Revista Floresta 14(2): 49-54.

Reissmann, C.B.; Radomski, M.I. \& Quadros, R.M.B. 1994. Relação entre os teores totais e a fração hidrossolúvel dos elementos $\mathrm{K}, \mathrm{Ca}, \mathrm{Mg}, \mathrm{Fe}, \mathrm{Mn}, \mathrm{Cu}, \mathrm{Zn}$ e Al em folhas de erva-mate (Ilex paraguariensis, St. Hil.). Brazilian Archives of Biology and Technology 37(4): 959-971.

Rode, M.W. 1993. Leaf nutrient accumulation and turnover at three stages of succession from heathland to forest. Journal of Vegetation Science 4(2): 263-268.

Rode, M.W. 1995. Aboveground nutrient cycling and forest development on poor sandy soil. Plant and Soil 168/169: 337-343. 
Rodin, L.E. \& Bazilivic, N.I. 1967. Production and mineral cycling in terrestrial vegetation. Edinburgh, Oliver and Boyd.

Salimon, C.I. \& Negrelle, R.R.N. 2001. Natural regeneration in a quaternary coastal plain in southern Brazilian Atlantic Rain forest. Brazilian Archives of Biology and Technology 44(2): 155-163.

Scheffer, F. \& Schachtschabel, P. 1973. Lehrbuch der Bodenkunde. Stuttgart, Ferdinad Enke.

Sobrado, M.A. \& Medina, E. 1980. General morphology, anatomical structure, and nutrient content of sclerophyllous leaves of the "bana" vegetation of Amazonas. Oecologia 45: 341-345.

Stark, N. 1970. The nutrient content of plants and soils from Brazil ans Surinam. Biotropica 2(1): 51-60.

Tedesco, M.J.; Gianello, C.; Bissani, C.A.; Bohnen, H. \& Volkweiss, S.J. 1995. Análises de solo, plantas e outros materiais. Boletim Técnico n. 5. Porto Alegre, Editora da Universidade Federal do Rio Grande do Sul.

Thompson, J.; Proctor, J.; Viana, V.; Milliken, W.; Ratter, J.A. \& Scott, D.A. 1992. Ecological studies on a lowland evergreen rain forest on Maracá Island, Roraima, Brazil. I. Physical environment, forest structure and leaf chemistry. Journal of Ecology 80: 689-703.

Tilman, D. 1985. The resource ratio hypothesis of succession. American Naturalist 125(6): 827-852.

Turner, I.M.; Ong, B.L. \& Tan, H.T.W. 1995. Vegetation analysis, leaf structure and nutrient status of a Malaysian heath community. Biotropica 27(1): 2-12.
Uhl, C.; Clark, K.; Clark, H. \& Murphy, P. 1981. Early plant succession after cutting and burning in the upper Rio Negro region of the Amazonian basin. Journal of Ecology 69: 631-649.

Uhl, C. \& Jordan, C.F. 1984. Succession and nutrient dynamics following forest cutting and burning in Amazonia. Ecology 65: 1476-1490.

Veloso, H.P.; Rangel Filho, A.L.R. \& Lima, J.C.A. 1991. Classificação da vegetação brasileira, adaptada a um sistema universal. Rio de Janeiro, IBGE.

Villela, D.M. \& Proctor, J. 1999. Litterfall mass, chemistry, and nutrient retranslocation in a monodominant forest on Maracá Island, Roraima, Brazil. Biotropica 31(2): 198-211.

Vitousek, P.M. \& Sanford Jr., R.L. 1986. Nutrient cycling in moist tropical forest. Annual Review of Ecology and Systematics 17: 137-167.

Volk, G.M.; Lynch-Holm, V.J.; Kostman, T.A.; Goss, L.J. \& Franceschi, V.R. 2002. The role of druse and raphide calcium oxalate crystals in tissue calcium regulation in Pistia stratiotes leaves. Plant Biology 4: 34-45.

Waring, R.H. \& Schlisinger, W.H. 1985. Forest Ecosystems. Concepts and management. Orlando, Academic Press, Inc. Harcourt Brace Jovanovich Publishers.

Whitmore, T.C. 1998. An introduction to tropical rain forests. Oxford, Oxford University Press.

Zangaro, W.; Nisizaki, S.M.A.; Domingos, J.C B. \& Nakano, E.M. 2003. Mycorrhizal response and successional status in 80 woody species from south Brazil. Journal of Tropical Ecology 19(3): 315-324. 